\title{
Erratum to: Dehydration rate and time of desiccation affect recovery of the lichen alga Trebouxia erici: alternative and classical protective mechanisms
}

Francisco Gasulla $\cdot$ Pedro Gómez de Nova .

Alberto Esteban-Carrasco $\cdot$ José M. Zapata •

Eva Barreno • Alfredo Guéra

Published online: 20 October 2009

(C) Springer-Verlag 2009

Erratum to: Planta

DOI 10.1007/s00425-009-1019-y

Unfortunately, the article was published with some errors.

1. Article title should read as 'Dehydration rate and time of desiccation affect recovery of the lichen alga Trebouxia erici: alternative and classical protective mechanisms', instead of 'Dehydration rate and time of desiccation affect recovery of the lichenic algae Trebouxia erici: alternative and classical protective mechanisms'.

2. Figure 7, part figures $b$ and $c$ were interchanged in the published version. Here are the corrected version of Fig. $7 b$ and $c$.
3. In the reference of Fridl T, Büdel B (2008) had a spell error for author Fridl, the correct spelling for the first author is 'Friedl'.

4. Additionally author would like to add missing acknowledgement section.

\section{Acknowledgments}

This project was funded by the Spanish Ministry of Education and Science (REN 2003-04465, CGL2006-12917-C01/02), and Generalitat Valenciana [PROMETEO 174/2008 GVA].

The online version of the original article can be found under doi:10.1007/s00425-009-1019-y.

F. Gasulla $\cdot$ P. G. de Nova $\cdot$ E. Barreno

Dpto. de Botánica, Fac. de Biología,

Instituto Cavanilles de Biodiversidad y Biología Evolutiva,

Universitat de València, 46100 Burjassot, Valencia, Spain

A. Esteban-Carrasco · J. M. Zapata · A. Guéra $(\bowtie)$

Dpto. de Biología Vegetal, Fac. de Biología,

Universidad de Alcalá, Edificio de Ciencias,

Campus Universitario, 28871 Alcalá de Henares,

Madrid, Spain

e-mail: alfredo.guera@uah.es 

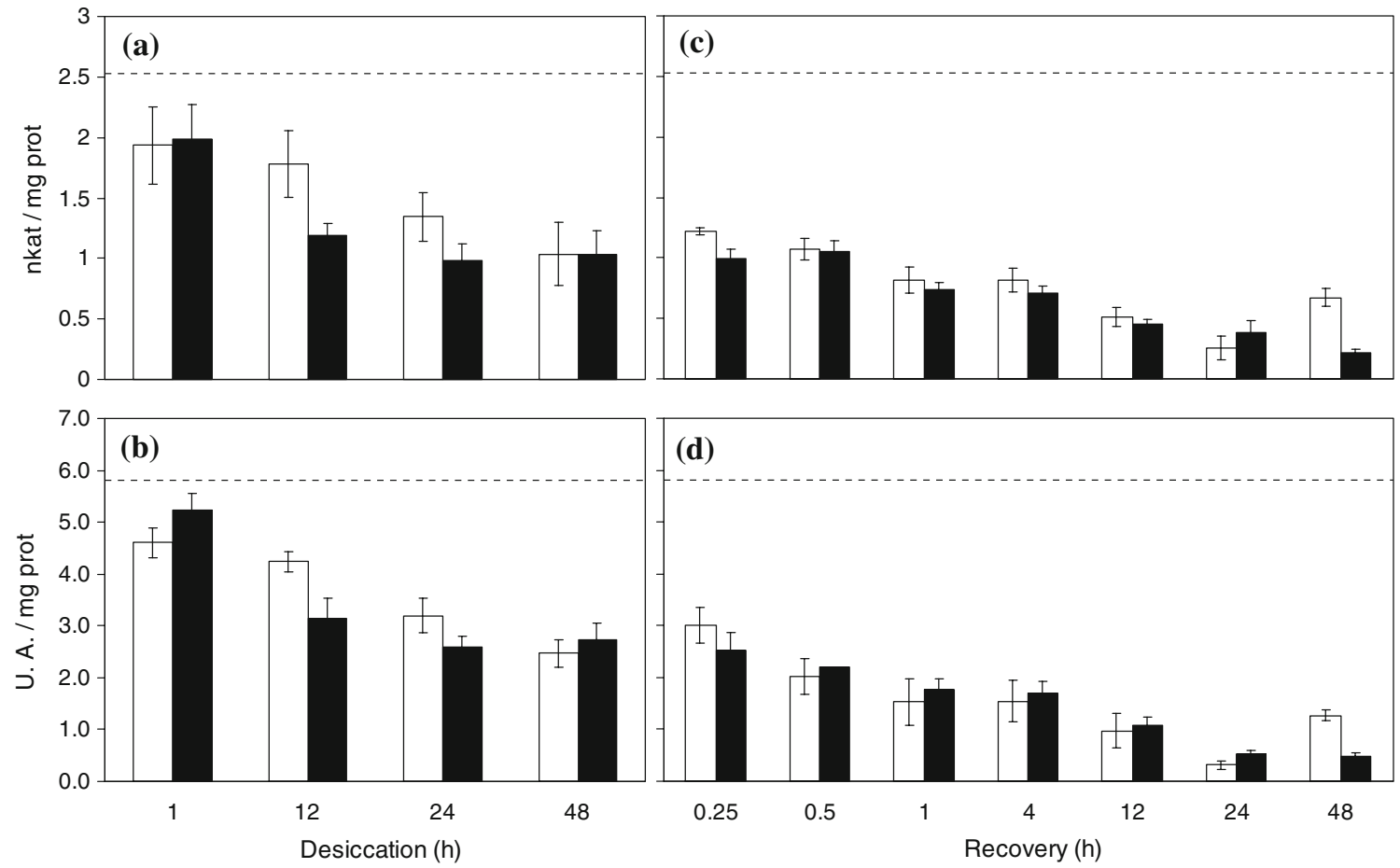